\title{
Study of Knowledge Innovation Driven by the Strategy of Innovation
}

\author{
Qichun Liu
}

The Institute of Marxism of Hubei University of Chinese Medicine, Wuhan City, Hubei Province, 430065, China.

Keywords: Knowledge Innovation; connotation; characteristic; revelation.

\begin{abstract}
Only on the condition that we analyze and reveal new features and laws, grasp the new tendency of knowledge innovation and drive the development with "innovation" based on the combination of Marx' innovation theory and the practice of China innovation strategies, we can gradually find the way to develop the Chinese characteristic of knowledge innovation.
\end{abstract}

\section{Introduction}

Although Marx and Engels did not clearly put forward such concepts as "innovation" and "knowledge innovation", the Marxist theory contains innovation judgment, innovation idea and innovation thought. Only on the condition that we analyze and reveal new features and laws, grasp the new tendency of knowledge innovation and drive the development with "innovation" based on the combination of Marx' innovation theory and the practice of China innovation strategies, we can gradually find the way to develop the Chinese characteristic of knowledge innovation.

\section{Basic Features and Forms of Marx's Innovation}

On the basis of critically inheriting the predecessors, Marx and Engels constructed their own theoretical system. A series of extraordinarily rich innovative ideas, innovative judgments, innovative ideas and innovative thoughts are contained in the Marxist theoretical system, which shows that it is itself a model of innovation.

\subsection{Basic features of Marx's Innovation.}

Marx believed that anything other than human beings could never be the subject of innovation. The subject of innovation can only be people living in certain social and historical conditions and social groups. Abstract, biological people cannot be the subject of innovation. Marx believed that people's innovation activities should follow the premise that both the objective scale of external things and the inner scale of human beings are consistent. Human innovation activities should be carried out in a planned way with a certain purpose and freedom. Moreover, in Marx's view, innovation was a pioneering high-level practice. It must be something that has never been done before. Because innovation requires more knowledge and wisdom and is much more complex and sophisticated than general practice. In conclusion, the basic characteristics of innovation are as follows: first, the subject of innovation must be a living and realistic person. Second, any innovation is an active practical activity, and it is a purposeful and planned activity of real people. Thirdly, innovation is a kind of creative advanced practice activity.

\subsection{Marx's Basic Form of Innovation.}

Marx believed that human practical activities are of various kinds and forms, but these forms cannot be separated from material production practice, social relations production practice and spiritual production practice. The three levels of innovation roughly corresponding to the three practices are scientific innovation, technological innovation and institutional innovation.

Marx analyzed, revealed and demonstrated the dialectical relationship between technological innovation, institutional innovation and scientific innovation, pointing out that they influence, promote and are inseparable. First, technological innovation and institutional innovation interact and promote each other. Technological innovation determines system innovation to some extent. System innovation restricts and influences technological innovation. In Marx's opinion, technological 
innovation is often in the real productivity level, is the first productivity. System innovation focuses on the adjustment and revolutionary influence of production relations. Secondly, on the capitalist production platform, Marx analyzed and demonstrated the relationship between scientific innovation and technological innovation, which is not only integrated but also promoted. On the one hand, scientific innovation emphasizes basic theoretical knowledge. Every scientific advance can be the soil and foundation for new productivity and improved production methods [1]. On the other hand, technological innovation provides strong support and experimental demonstration for scientific innovation. Every success in technological innovation is a successful test of scientific theory. Third, for scientific innovation and institutional innovation, Marx believed that they are also a mutually reinforcing relationship. Only through the innovation of scientific theories can it be possible to turn wisdom and intelligence into real productivity. Thus, the change of production tools and modes of production will be caused, and then the institutional change of production relations will be caused. System innovation will affect the development of scientific innovation. Because any innovation activity is subject to various objective conditions in the real society, it is difficult to be unaffected by social relations, including the ownership of the means of production.

Therefore, Marx and Engels have always regarded knowledge innovation and technological progress as a powerful lever and revolutionary force for historical development. Based on the theoretical system of Marxism about innovative ideas, the author believed that the innovation of Marx's understanding, is the reality person in a planned way, purposefully, free consciously practice, and has a certain value, the activities of the new ideas in pioneering new theory achievement process. The general manifestations are scientific innovation, technological innovation, and institutional innovation. As a creative practice, the basic characteristics of innovation include "human subject" and "human nature".

\section{Connotation and Characteristics of Knowledge Innovation}

Knowledge innovation is the ladder for the development and progress of human civilization, the perpetual motive and inexhaustible source of social development and economic prosperity. The development of human society is accompanied by the innovation of knowledge, and it is knowledge innovation that causes the great leap of social productivity. Knowledge innovation involves a wide range of complex fields that can occur in any area of human production and life.

\subsection{Connotation of Knowledge Innovation.}

Schumpeter, an American scholar, first proposed the "innovation theory" in the economic sense. After defining the concept of innovation scientifically, he also constructs the theoretical paradigm, which has great influence on the academic circle. In 1993, American scholar Emerton first proposed the concept of "knowledge innovation". He believes that knowledge innovation is for the success of enterprises, the vitality of national economy and the progress of society, the creation, evolution, exchange of new ideas, and the constant commercialization of new knowledge and ideas.

Combining with the Marx's concept of innovation, in essence, knowledge innovation is the main body for a particular purpose, pioneering, exploratory to create new knowledge, new ideas, new results of practice activities and process. Knowledge innovation is the dialectical unity of human cognition and practice, which may occur in any field of human production, life and even brain nerve. It is not so much a personal development process as a social development process [2]. It has great significance and value for economic development, human progress and knowledge innovation. From the following aspects can reflect its connotation.

(1) Knowledge innovation is the dialectical unity of human cognitive activities and practical activities, and it has the nature of regularity and purpose. Knowledge innovation comes from human cognition and practice. Only in the two-way cycle of human cognition and practice can new attributes, new ideas or new achievements of objective existence be gradually revealed and discovered [3]. If it is a fictional pure thinking activity, so, knowledge innovation is unlikely to improve people's living environment and promoting people's all-round development, therefore, the main body of knowledge innovation has very obvious practical and utilitarian value object and practicality. 
(2) Knowledge innovation is a pioneering, creative and exploratory process. As a conceptual activity process, innovation means new ideas, new thinking, new inventions and new achievements. All innovation is a kind of change, which means the death of old things and the birth of new things. In other words, innovation itself must be innovative, exploratory and novel. New judgments, new technologies, new achievements, new thinking and other "new" things must be more or less reflected.

(3) Knowledge innovation has the characteristics of The Times. Generally speaking, the connotation and extension of knowledge will change with the change of The Times. Because knowledge itself is multidimensional and dynamic. Because of this, knowledge innovation will also change, showing the characteristics of The Times. No matter from innovation domain, innovation content and innovation way and so on, this characteristic is reflected incisively and vividly. In the contemporary era, with the development of science and technology, knowledge innovation covers more and more fields and diversified ways.

\subsection{Characteristics of Knowledge Innovation.}

As mentioned above, knowledge innovation, as a practical activity process to improve the real world, is generally dominated by knowledge progress and actively utilized. Only by grasping the characteristics of knowledge innovation can positive and effective measures be taken to protect, motivate and promote knowledge innovation.

(1) Novelty and originality. Knowledge innovation will not come from the sky, nor will it be accomplished by temporary and temporary exploration. Because the knowledge is endless, has the inheritance characteristic. The knowledge of the ancients provided the basis and direction for the existing knowledge and also determined the logical direction and trend of the future knowledge. That is to say, every progress of human beings is made on the basis of the knowledge accumulated by our predecessors. No matter which time the knowledge innovation, is full of years of knowledge accumulation and innovative thinking. It can be seen that knowledge innovation is a dynamic process of diverse changes, bearing the ever-changing factors, and each link flashing the light of human wisdom. In the knowledge society, knowledge innovation often needs to integrate all kinds of factors, especially needs to create a unique way, create new ideas and bring forth new ideas.

(2) Social application. Knowledge has the characteristics of commodity and value. In the field of knowledge innovation, such characteristics as purposiveness, regularity and social applicability are particularly obvious. Because knowledge innovation is the practical process of knowledge. Knowledge innovation with purpose and value is not limited to the innovation of certain products and technologies of human beings, but more importantly to the application of the value of the entire human society. The social applicability of knowledge innovation includes the application of theory and practice.

(3) Contingency and uncertainty. The knowledge innovation explores the unknown field, and there is no solid experience to support it. Every innovation is a new exploration and experience. Therefore, contingency has become one of the characteristics of knowledge innovation. The uncertainty of knowledge itself leads to the uncertainty of knowledge innovation. Therefore, unpredictable values make it difficult to innovate. Unknown risks are difficult to grasp and constrain. It also makes innovation hard. It is precisely because of this difficulty and uncertainty that we need to think more comprehensively about the positive significance and social value of innovation activities. We shall establish a system of intellectual property, protection of innovation, to encourage more people to knowledge innovation activities, forming good social atmosphere of knowledge innovation, create the environment of knowledge innovation.

\section{Revelation}

In conclusion, as the crystallization of human integrated cognition and practice, knowledge innovation is a pioneering and exploratory cognition and practice activity. In any field of human production and life, there is no lack of knowledge innovation. Today, with the rapid development of science and technology, knowledge innovation has exerted a profound impact on the internal structure of productivity and the external environment. It has greatly promoted the progress of human 
society and raised the economic living standard of human beings [4]. As the innovation system, knowledge innovation, dynamic and multidimensional nature, only the knowledge creation, knowledge dissemination and knowledge application ability, is likely to promote the actual effect of knowledge innovation and the realization of knowledge innovation of social values.

With the rapid development of science and technology, international competition intensifying, the improvement of the complexity of the national innovation system structure, environmental factors and knowledge change frequency to speed up, we must strive to improve the efficiency of the national innovation system. In order to "place innovation at the core of national development and make innovation permeate all the work of the party and the country" [5], we must adhere to the combination of Marx's innovative thought and contemporary Chinese innovation practice. We must carry out and implement the new era of socialism with Chinese characteristics about innovative ideas, create national innovation system, consummate the mechanism to promote the independent innovation system, further implement the strategy of innovation, adhering to the "big five" development philosophy, reveals new laws and new characteristics of knowledge innovation, in-depth grasp the trend of the development of knowledge innovation. Only by leading and driving the overall development with "innovation" can we find the way of developing knowledge innovation with Chinese characteristics.

\section{References}

[1]. Complete works of Marx and Engels, vol. 47 [M]. Beijing: people's publishing house, 1979:570.

[2]. Liu Sichuan. Theory of intellectual productivity [M]. Changsha: Hunan people's publishing house, 2017:152.

[3]. Yang Changing: philosophical analysis of knowledge innovation [D]. Master's thesis of Dalian university of technology, 2005.

[4]. Liu Sichuan: philosophical thinking on intellectual productivity [D]. Doctoral dissertation of central China normal university, 2012.

[5]. Suggestions of the CPC central committee on formulating the 13th five-year plan for national economic and social development. Xinhua news agency Beijing, 2015-11. 